\title{
Are Steroids Still Useful in Immunosuppressed Patients With Inflammatory Bowel Disease? A Retrospective, Population-Based Study
}

\author{
Beatriz Sicilia $^{1 *}$, Lara Arias ${ }^{1}$, Gadea Hontoria ${ }^{1}$, Nieves García ${ }^{1}$, Ester Badia ${ }^{1}$ and \\ Fernando Gomollón ${ }^{2}$ \\ ${ }^{1}$ Hospital Universitario de Burgos, Burgos, Spain, ${ }^{2}$ Facultad de Medicina, Hospital Clínico Universitario, Instituto de \\ Investigación Sanitaria de Aragón, Ciberehd, Zaragoza, Spain
}

\section{OPEN ACCESS}

Edited by:

Yeong Yeh Lee,

Universiti Sains Malaysia

(USM), Malaysia

Reviewed by:

Nazri Mustaffa,

Universiti Sains Malaysia

(USM), Malaysia

Christian Philipp Selinger,

University Hospital of South

Manchester, United Kingdom

*Correspondence:

Beatriz Sicilia

bsicilia4@gmail.com

Specialty section:

This article was submitted to

Gastroenterology,

a section of the journal

Frontiers in Medicine

Received: 10 January 2021 Accepted: 02 June 2021

Published: 25 June 2021

Citation:

Sicilia B, Arias L, Hontoria G, García N, Badia E and Gomollón F (2021) Are Steroids Still Useful in Immunosuppressed Patients With Inflammatory Bowel Disease? A Retrospective, Population-Based

Study. Front. Med. 8:651685 doi: 10.3389/fmed.2021.651685
Background: Effectiveness of corticosteroids in immunosuppressed patients with inflammatory bowel disease (IBD) has not been completely elucidated.

Aims: To assess the effectiveness and examine the long-term follow-up of systemic or low-bioavailability oral steroid treatment for moderate flare-ups in patients treated with immunosuppressive drugs.

Methods: Immunosuppressed patients with inflammatory bowel disease (IBD) from our population-data registry were analyzed. For statistical analysis, the chi-square test, Mann-Whitney $U$ test, and Kaplan-Meier survival analysis were used as appropriate.

Results: A total of 392 patients with IBD and a median of 82 (range, 6-271) months of immunosuppressive (IMM) treatment were identified. The mean follow-up was 87 months (range, 6-239 months). A total of 89 patients (23\%) needed at least one steroid course during their follow-up. Average time from IMM to steroid treatment was 26 (range, 6-207) months. In patients with CD, fibrostenotic (B2) and fistulizing (B3) behaviors $[p=0.005$; odds ratio (OR): 2.284] were risk factors for using steroids after IMM treatment. In patients with UC, no statistically significant variables were identified. Of the 89 patients who received one first steroid course, 49 (55\%) stepped up to biological treatment or surgery after a median of 13 months (range, 0-178), 19 (21\%) were treated with repeated steroid courses, and 31 (35\%) required no further treatment. Patients with CD had a higher risk $(p=0.007$; OR: 3.529) of receiving biological treatment or surgery than patients with UC. The longer the patients with UC (more months) spent using steroids, the greater the risk of requiring treatment with biological drugs or surgery $(p=0.009)$.

Conclusion: A total of $23 \%$ of the immunosuppressed patients with IBD received at least one course of steroid treatment. In patients under immunosuppression treated with at least a course of steroids, CD patients were more likely stepped up to biologics and/or surgery than UC patients. In patients with CD, B2/B3 behavior pattern were significant risk factors. After one course of steroids only 35\% of immunosuppressed IBD patients remained in remission without needing treatment scalation.

Keywords: immunosuppression, corticosteroids, Crohn's disease, ulcerative colitis, inflammatory bowel diseases 


\section{INTRODUCTION}

In 1955, Truelove and Witts (1) were the first to demonstrate the efficacy of corticosteroids to induce remission in patients with inflammatory bowel disease (IBD): moderate to severe ulcerative colitis (UC) patients treated with hydrocortisone (100 mg/day) did have a clearly better response than those receiving placebo, with statistically significant differences in hard endpoints as mortality. Until now corticosteroids continue to be the most widely used drugs for the treatment of moderate and severe flare-ups in both Crohn's disease (CD) and UC $(2,3)$.

The main effects of systemic corticosteroids (prednisone or equivalent) are to induce remission of moderate and severe outbreaks in patients with CD [evidence level (EL) 1] (4) and UC (EL 1) (5), with high quality of evidence (QL) and strong recommendation (6). High doses of prednisone (40 mg/day-1 $\mathrm{mg} / \mathrm{kg}$ ) are usually prescribed. Different systemic drugs require specific doses, and parenteral route is sometimes preferred in severe cases. For low-bioavailability systemic corticosteroids, $9 \mathrm{mg}$ of oral budesonide is the treatment of choice to induce remission in patients with ileal CD, both in mild (EL 2) and moderate (EL 1) flares (4). In patients with UC and mild-to-moderate flare-ups without a response to mesalamine, beclomethasone at a minimum dose of $5 \mathrm{mg} /$ day (EL 2) (5) (low QL, weakly in favor) (6) or multimatrix budesonide at a dose of 9 $\mathrm{mg} /$ day (EL 2) can be used (Table 1). Steroid-resistance (primary failure) and steroid-dependence are common and defined in ECCO guidelines (4).

Thiopurine immunosuppressant drugs (azathioprine or mercaptopurine) are effective for patients with corticosteroiddependence and have helped patients achieve a withdrawal rate from corticosteroids of almost 60\% (7). Corticosteroids are frequently used in patients already under immunosuppressive (IMM) treatment for controlling a new flare-up. However, scant data are available on the efficacy of corticosteroid use in this scenario. In fact, main published studies have shown that $40-50 \%$ of patients receive corticosteroid treatment and that $20-30 \%$ receive immunomodulatory treatment $(8-11)$. A recent Canadian study of 3,312 patients with IBD in clinical practice between 1994 and 2014 (12) showed that corticosteroids were prescribed in the first year of IMM treatment for $20 \%$ of patients with CD and up to $40 \%$ of patients with UC. Steroids have significant toxicity, especially in the long-term. Data on their effectiveness in daily clinic could help for designing new protocols of use.

We do present our clinical experience with the use of steroids in a retrospective study of all the patients from our IBD Unit.

\section{AIMS}

Our first aim was to evaluate the effectiveness of systemic oral (prednisone) and low-bioavailability (beclomethasone/budesonide) corticosteroids to induce

Abbreviations: CD, Crohn's disease; CI, confidence interval; EL, evidence level; IBD, inflammatory bowel disease; IMM, immunosuppressive; OR, odds ratio; UC, Ulcerative colitis. remission of moderate IBD flare-ups in patients with at least 6 months of IMM treatment (azathioprine, mercaptopurine, or methotrexate). Our second aim was to assess the long-term effectiveness of this treatment in avoiding the need for biological drugs and/or surgery and analyzing the predictors of response in this specific scenario.

\section{METHODOLOGY}

We used a population database to identify patients diagnosed with IBD (both UC and CD) between 1966 and 2016 from a reference area of 176,208 inhabitants [Spanish Statistical Office (INE) 2016]; we included only patients who had at least 6 months of IMM treatment in our study.

We performed a descriptive analysis and collected the following variables:

- Type of IBD (UC/CD)

- Year of diagnosis

- Location of IBD according to the Montreal classification for $\mathrm{UC}$ and CD:

- Extensive UC (E3)/left-sided (E2)/ulcerative proctitis (E1)

- Ileal CD (L1)/colonic (L2)/ileocolonic (L3) with/without isolated upper disease (L4)

- Presence of perianal disease

- Behavior pattern according to the Montreal classification for CD:
- Inflammatory
pattern
(B1)/fibrostenotic (B2)/penetrating (B3)

- Appendectomy

- Smoking habit at diagnosis:

- Smoker: Smoker at the start of IMM and current treatment

- Former smoker: At least 6 months without smoking

- Non-smoker: Never smoked or $>10$ years without smoking

- Previous surgery

- Use of corticosteroids at diagnosis

- IMM treatment

- Type of IMM treatment: azatioprine, mercaptopurine, methotrexate

- IMM treatment time until the use of corticosteroids and until the end of follow-up

- Treatment with biological drugs prior to immunosuppression

During the follow-up, we recorded the following:

- Treatment with systemic oral or low-bioavailability corticosteroids, dosage, and time

- The efficacy of treatment with corticosteroids, which was defined as not requiring further cycles of corticosteroids, escalation of treatment, or surgery

- The amount of time in which no rescue therapy was necessary after the use of corticosteroids

- Any need for biologic drugs, surgery, or further corticosteroid cycles. 
TABLE 1 | Level of evidence and indications for use of corticosteroids in patients with IBD.

\begin{tabular}{|c|c|c|c|c|}
\hline & Flare-up & Corticosteroid & ECCO & GRADE \\
\hline \multirow[t]{3}{*}{ UC } & Mild-moderate & Beclomethasone $5 \mathrm{mg} / \mathrm{d}$ & EL 2 & $\begin{array}{l}\text { QL low } \\
\text { RG Weak for }\end{array}$ \\
\hline & Mild-Moderate & Prednisone 1 mg/kg & EL 1 & $\begin{array}{l}\text { QL moderate } \\
\text { RG Strong for }\end{array}$ \\
\hline & Severe & Prednisone $1 \mathrm{mg} / \mathrm{kg}$ & EL 1 & $\begin{array}{l}\text { QL high } \\
\text { RG Strong for }\end{array}$ \\
\hline \multirow{3}{*}{$C D$} & Moderate ileocecal & Budesonide 9 mg/d & EL 1 & - \\
\hline & Moderate-severe & Prednisone 1 mg/kg & EL 1 & - \\
\hline & Severe & Prednisone 1 mg/kg & EL 1 & - \\
\hline
\end{tabular}

QL, Quality of evidence; EL, Evidence level; RG, Recommendation Grade.

TABLE 2 | Baseline patient demographics and disease characteristics.

\begin{tabular}{|c|c|c|c|}
\hline IMM Treatment $>6$ Months & $\begin{array}{l}\text { CD 260 } \\
(66 \%)\end{array}$ & $\begin{array}{l}\text { UC } 132 \\
(34 \%)\end{array}$ & Total 392 (100\%) \\
\hline Gender (male) & 136 (52\%) & $71(54 \%)$ & 207 (53\%) \\
\hline Behavior & $\begin{array}{l}57 \% \text { B1/43\% B2-3 } \\
25 \% \text { perianal disease }\end{array}$ & & \\
\hline \multirow[t]{3}{*}{ Smoke habit } & Smoker 84 (32\%) & Smoker 17 (13\%) & Smoker 101 (26\%) \\
\hline & Former smoker 50 (19\%) & Former smoker 12 (9\%) & Former smoker 62 (16\%) \\
\hline & Non-smoker 126 (48\%) & Non-smoker 103 (78\%) & Non-smoker 229 (58\%) \\
\hline Steroids at Dg & 200 (77\%) & 104 (79\%) & 304 (78\%) \\
\hline Biological before IMM treatment & $4(2 \%)$ & $0(0 \%)$ & $4(2 \%)$ \\
\hline Biologic follow-up & 27 (10\%) & $9(7 \%)$ & $35(9 \%)$ \\
\hline
\end{tabular}

Activity of the disease was defined clinically first with physicianbased subjective evaluation and then Harvey-Bradshaw index in $\mathrm{CD}$ ( $<4$ points defined as clinical remission) and Truelove-Wits index in UC (remission if $<3$ bowel movements/day and no rectal bleeding). The goal of treatment was clinical remission, and steroids prescribed to obtain remission if clinical activity present. Protocol for steroids in our hospital followed textbook and GETECCU (www.geteccu.org) recommendations in the first years (1966-2006) and ECCO guidelines from 2006 to 2016. In brief, moderate to severe CD or UC were treated with prednisone, with $1 \mathrm{mg} / \mathrm{kg} /$ day starting dose, and tapering from week 4 (usually reducing $10 \mathrm{mg} /$ day every week). Mild to moderate ileitis was treated with budesonide $(9 \mathrm{mg} /$ day, tapering from week 4). Mild to moderate cases of UC were treated with oral beclomethasone (5-10 mg/day; 1-2 months course).

Patients were treated at the discretion of the responsible physician. In most cases IBD patients were under the care of the same expert gastroenterologist from 1966 to
2010. After 2010 the team responsible for IBD patients has remained constant, following ECCO guidelines as gold-standard. Biologics were available from several months $(<12)$ after EMA approval. Azathioprine was given at $2.5-3 \mathrm{mg} / \mathrm{kg} / \mathrm{day}$ in one dose, and mercaptopurine at $1.5 \mathrm{mg} / \mathrm{kg} / \mathrm{day}$. In both cases doses were adjusted if needed by frequent (every 3-6 months) blood tests follow-up, but no metabolites determination was available.

For statistical analysis, all data were processed using the IBM SPSS 19 statistical software with a confidence interval of $95 \%$. The data had been previously collected and processed using Microsoft Office Excel 2010. Descriptive analysis of the sample was performed and showed the means (standard deviation), medians (interquartile range), and frequency (percentage) according to the characteristics and distributions of variables. Differences between variables were evaluated using the chi-square (Fisher) test for qualitative variables and Student's $t$-test, provided it verified the conditions of use; otherwise, the corresponding 
TABLE 3 | Variables associated with the need for treatment with corticosteroids in patients who have received at least 6 months of immunosuppressant treatment.

\begin{tabular}{|c|c|c|c|c|}
\hline Variables & & \multicolumn{3}{|c|}{ Post-IMM treatment corticosteroids } \\
\hline Sex & Female & $143(47 \%)$ & $42(47 \%)$ & \\
\hline Age & & 47.6 & 49.66 & 0.242 \\
\hline Corticosteroids at diagnosis & No & 72 (24\%) & $14(16 \%)$ & 0.102 \\
\hline Current diagnosis & $C D$ & $200(66 \%)$ & $60(67 \%)$ & \\
\hline \multirow[t]{3}{*}{ UC location } & E3 & $49(48 \%)$ & $20(69 \%)$ & 0.097 \\
\hline & E2 & $50(49 \%)$ & $9(31 \%)$ & \\
\hline & E1 & $4(4 \%)$ & $0(0 \%)$ & \\
\hline CD location & L3 & $41(21 \%)$ & $6(10 \%)$ & 0.105 \\
\hline \multirow[t]{2}{*}{ Pattern } & B1 & $76(38 \%)$ & $35(58 \%)$ & 0.005 \\
\hline & B2/B3 & $124(62 \%)$ & $25(42 \%)$ & OR: 2.284 \\
\hline \multirow[t]{2}{*}{ Perianal disease } & No & $258(85 \%)$ & $69(78 \%)$ & 0.089 \\
\hline & Yes & 45 (15\%) & $20(22 \%)$ & \\
\hline \multirow[t]{2}{*}{ Extra-intestinal manifestations } & No & $244(81 \%)$ & $72(82 \%)$ & 0.918 \\
\hline & Yes & $56(15 \%)$ & $16(18 \%)$ & \\
\hline \multirow[t]{2}{*}{ Biological drugs prior to IMM treatment } & No & $302 \%)$ & $86(97 \%)$ & 0.038 \\
\hline & Yes & $1(0 \%)$ & $3(3 \%)$ & \\
\hline \multirow[t]{2}{*}{ Surgery prior to IMM treatment } & No & 257 (85\%) & $71(80 \%)$ & 0.258 \\
\hline & Yes & $46(15 \%)$ & $18(20 \%)$ & \\
\hline
\end{tabular}

The bold values highlight the variables which are statistically significative.

non-parametric tests were used, Mann-Whitney $U$ test or Kruskal-Wallis, if one of the variables was quantitative.

Finally, survival analysis was performed using the KaplanMeier curve and comparing different survival curves according to the diagnosis of UC or CD using the log-rank hypothesis test, which tests the null hypothesis that the two groups compared have the same survival curves.

\section{RESULTS}

We identified 904 patients with IBD in our population database from 1966 to 2016 and selected 392 (43.3\%) who had at least 6 months of IMM treatment, with a mean duration of 82 months (6-271). Of these 392 patients, 260 were diagnosed with CD (66\%) and 132 were diagnosed with UC (34\%). We describe the demographic and clinical characteristics of the patients in Table 2.

A total of 89 patients $(23 \%)$ were treated with at least one course of oral corticosteroids during their follow-up, with an average duration of 4 months (1-168 months). Of these 89 patients, $63 \%$ received treatment with systemic corticosteroids and $37 \%$ with low-bioavailability oral corticosteroids; a total of 29 patients (33\%) had UC, and 60 patients (67\%) had CD $(p=0.805)$.

A comparison of the variables associated with the need for treatment with corticosteroids (Table 3) showed no differences with regard to sex, age, location of the disease, perianal disease, appendectomy, extra-intestinal manifestations, smoking habits, previous use of corticosteroids, and previous surgery. Fibrostenotic (B2) and fistulizing (B3) patterns of CD ( $p=$ 0.005 ) behaved as a statistically significant variable. A patient with a fibrostenotic or fistulizing pattern of CD (B2-B3) was twice as likely to take corticosteroids while on IMM treatment than a patient with an inflammatory pattern of CD (B-1) [odds ratio (OR): 2.284] (Figure 1). A total of 4 patients (1\%) with $\mathrm{CD}$ required treatment with a biological drug prior to starting their IMM treatment (a top-down strategy), and this was also associated with the need for taking corticosteroids during evolution $(p=0.038)$. 


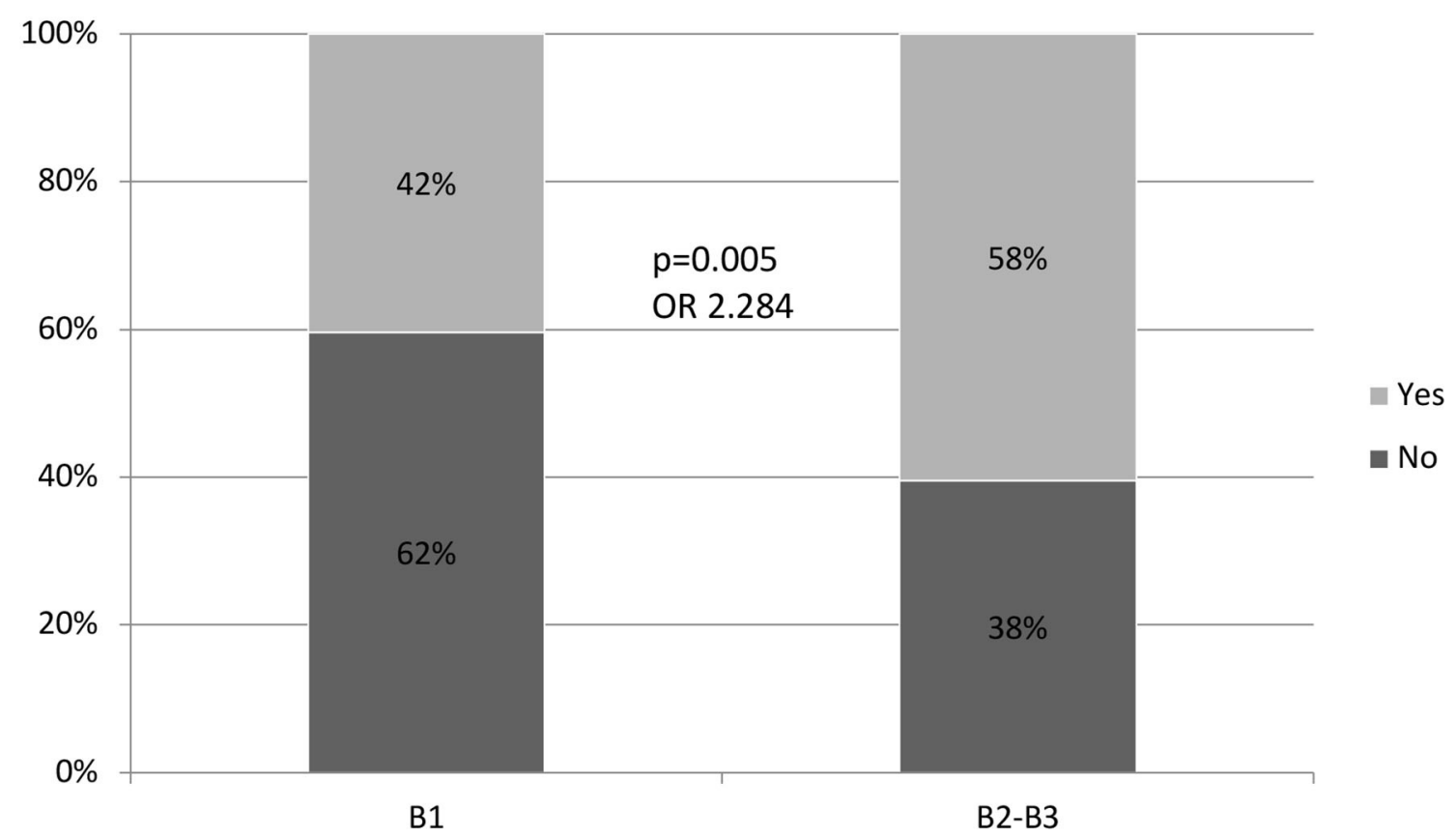

FIGURE 1 | Relation between the pattern of behavior and the need for treatment with corticosteroids.

A total of 49 patients (55\%), who were on IMM treatment and treated with corticosteroids for a moderate flare-up of their disease, required biological treatment or surgery during their average follow-up period of 40 months (1-178 months); a total of 19 patients $(21 \%)$ required more than 1 cycle of corticosteroids. The mean length of time from taking the immunosuppressant drug to the use of corticosteroids was 26 months (6-207). There is no predictive variable of corticosteroid efficacy in patients with CD, but there is a directly proportional association between the time of corticosteroid use and the need for treatment with biological drugs or surgery in the follow-up of patients with UC (Tables 4, 5).

A single cycle of corticosteroids was effective in 31 patients (35\%), and no other type of treatment was needed in these patients during their follow-up period, such as further cycles of corticosteroids, biologics, or surgery.

A comparison of the variables associated with the need for biological drugs or surgery showed a higher risk of treatment with a biological drug or surgery after initial corticosteroid treatment in patients with $\mathrm{CD}$ than in patients with UC $(p=0.007$; OR: 3.529 ) (Figure 2). Of the 89 patients who required treatment with corticosteroids, 10 with UC (20\%) and 39 with CD (80\%) needed rescue therapy throughout their follow-up. This difference was maintained when analyzing the probability of not requiring any type of treatment, including repeat cycles of corticosteroids ( $p=$ 0.005) (Figure 3).

In the survival analysis (Figure 4), we observed a 50\% chance of not requiring biological drugs or surgery at 130 months. When comparing survival between patients with $\mathrm{CD}$ and those with UC (Figure 5), we observed a clear separation between both curves, but they crossed at certain periods $(p=0.078)$; however, survival without salvage therapy was higher in patients with UC. The $50 \%$ chance of not receiving any type of treatment after receiving corticosteroids lasted 83 months longer (range 97180 ) in patients with UC compared to those with CD (Table 6). We observed a $75 \%$ probability of not needing any additional treatment for 62 months in patients with UC and for 36 months in patients with CD (Table 7).

\section{DISCUSSION}

The use of corticosteroids in our patients who had responded to IMM treatment reached 55\%, with no differences between patients with UC and patients with $\mathrm{CD}$, and $21 \%$ required more than one course of corticosteroids. We believe this percentage is likely higher than in current clinical practice, because our review was retrospective and included years when biological drugs were not yet in use. The pivotal published studies (8-11) report corticosteroid treatment in $40-50 \%$ of patients enrolled in clinical trials, and $\sim 30 \%$ did not respond to IMM treatment. The only randomized clinical trial that reported this associated data was the GEMINI 1 (9), where $17-21 \%$ of the patients included in the different treatment arms were receiving IMM treatment and taking corticosteroids concurrently.

Reinforcing the results of other published cohorts (13), the results of our study show that the fibrostenotic and fistulizing patterns in $C D$ are statistically significant factors associated with the need for corticosteroid treatment in immunosuppressed patients; likely because this reflects a greater severity in the clinical evolution of this behavior pattern and has been reflected in follow-up, epidemiological-incident cohort studies (14). However, compared to the inflammatory pattern, this pattern 
TABLE 4 | Requirement for rescue therapy with biological drugs/surgery in immunosuppressed patients with UC who have needed treatment with corticosteroids.

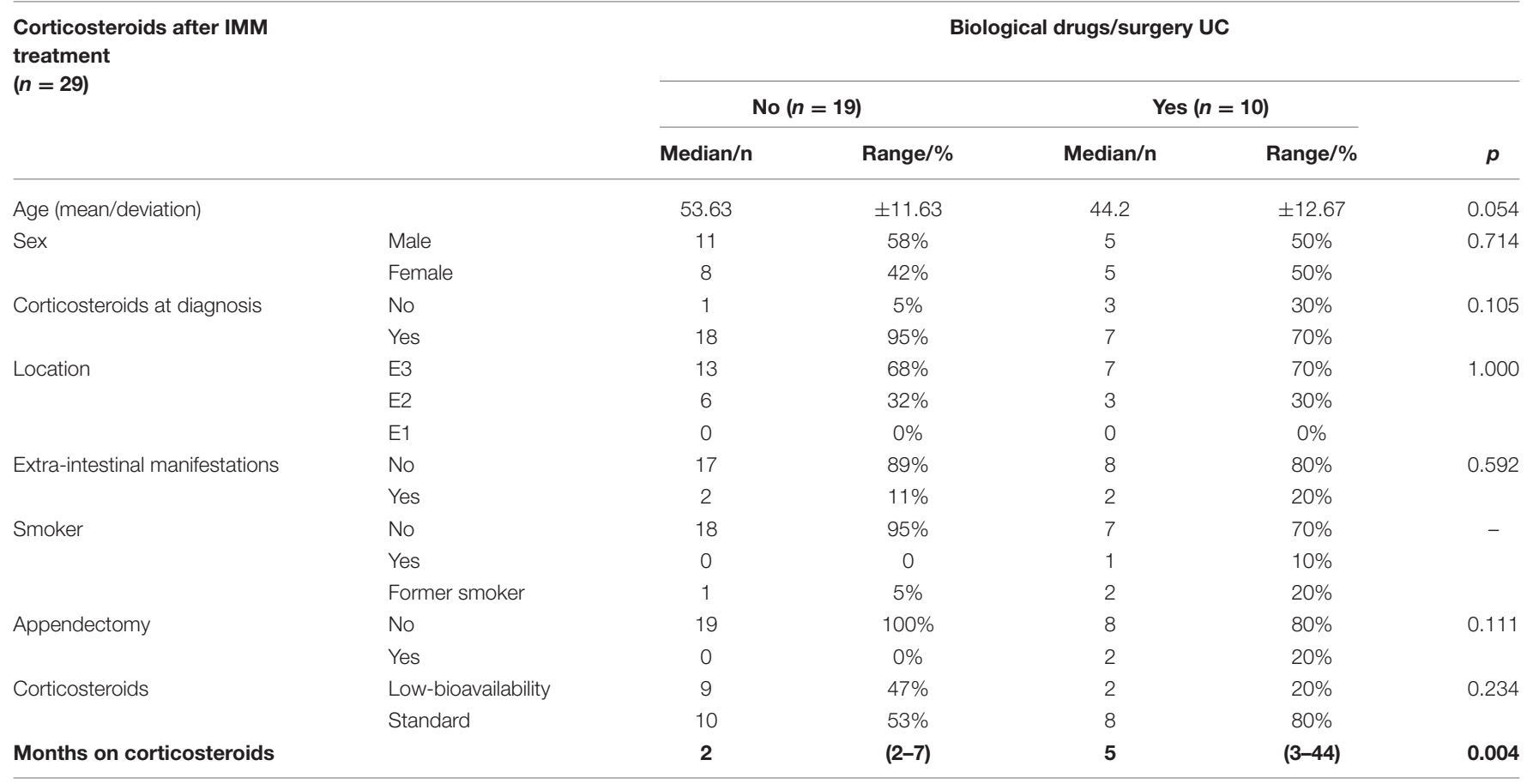

The bold values highlight the variables which are statistically significative.

TABLE 5 | Requirement for rescue therapy with biological drugs/surgery in immunosuppressed patients with CD who have needed treatment with corticosteroids.

Corticosteroids after IMM treatment $(n=60)$

Biological drugs/surgery CD

\begin{tabular}{|c|c|c|c|c|c|c|}
\hline & & \\
\hline & & \multicolumn{2}{|c|}{ No $(n=21)$} & \multicolumn{2}{|c|}{ Yes $(n=39)$} & $p$ \\
\hline \multirow[t]{2}{*}{ Sex } & Male & 10 & $48 \%$ & 21 & $54 \%$ & 0.645 \\
\hline & Female & 11 & $52 \%$ & 18 & $46 \%$ & \\
\hline Corticosteroids at diagnosis & No & 5 & $24 \%$ & 5 & $13 \%$ & 0.298 \\
\hline \multirow[t]{3}{*}{ Location } & Colonic & 4 & $19 \%$ & 2 & $5 \%$ & - \\
\hline & lleal & 9 & $43 \%$ & 18 & $46 \%$ & \\
\hline & Ileocolonic & 8 & $38 \%$ & 19 & $49 \%$ & \\
\hline \multirow[t]{2}{*}{ L4 } & No & 18 & $86 \%$ & 28 & $72 \%$ & 0.340 \\
\hline & Yes & 3 & $14 \%$ & 11 & $28 \%$ & \\
\hline \multirow[t]{2}{*}{ Perianal disease } & No & 14 & $67 \%$ & 26 & $67 \%$ & 1.000 \\
\hline & Yes & 7 & $33 \%$ & 13 & $33 \%$ & \\
\hline \multirow[t]{3}{*}{ Smoker } & No & 12 & $57 \%$ & 23 & $59 \%$ & \\
\hline & Yes & 5 & $24 \%$ & 12 & $31 \%$ & \\
\hline & Former smoker & 4 & $19 \%$ & 4 & $10 \%$ & \\
\hline \multirow[t]{2}{*}{ Appendectomy } & No & 11 & $58 \%$ & 21 & $55 \%$ & 0.850 \\
\hline & Yes & 8 & $42 \%$ & 17 & $45 \%$ & \\
\hline \multirow[t]{2}{*}{ Corticosteroids } & Low-bioavailability & 10 & $48 \%$ & 12 & $31 \%$ & 0.196 \\
\hline & Standard & 11 & $52 \%$ & 27 & $69 \%$ & \\
\hline Months on corticosteroids & & 4 & $(2-30)$ & 4 & $(1-168)$ & 0.511 \\
\hline
\end{tabular}




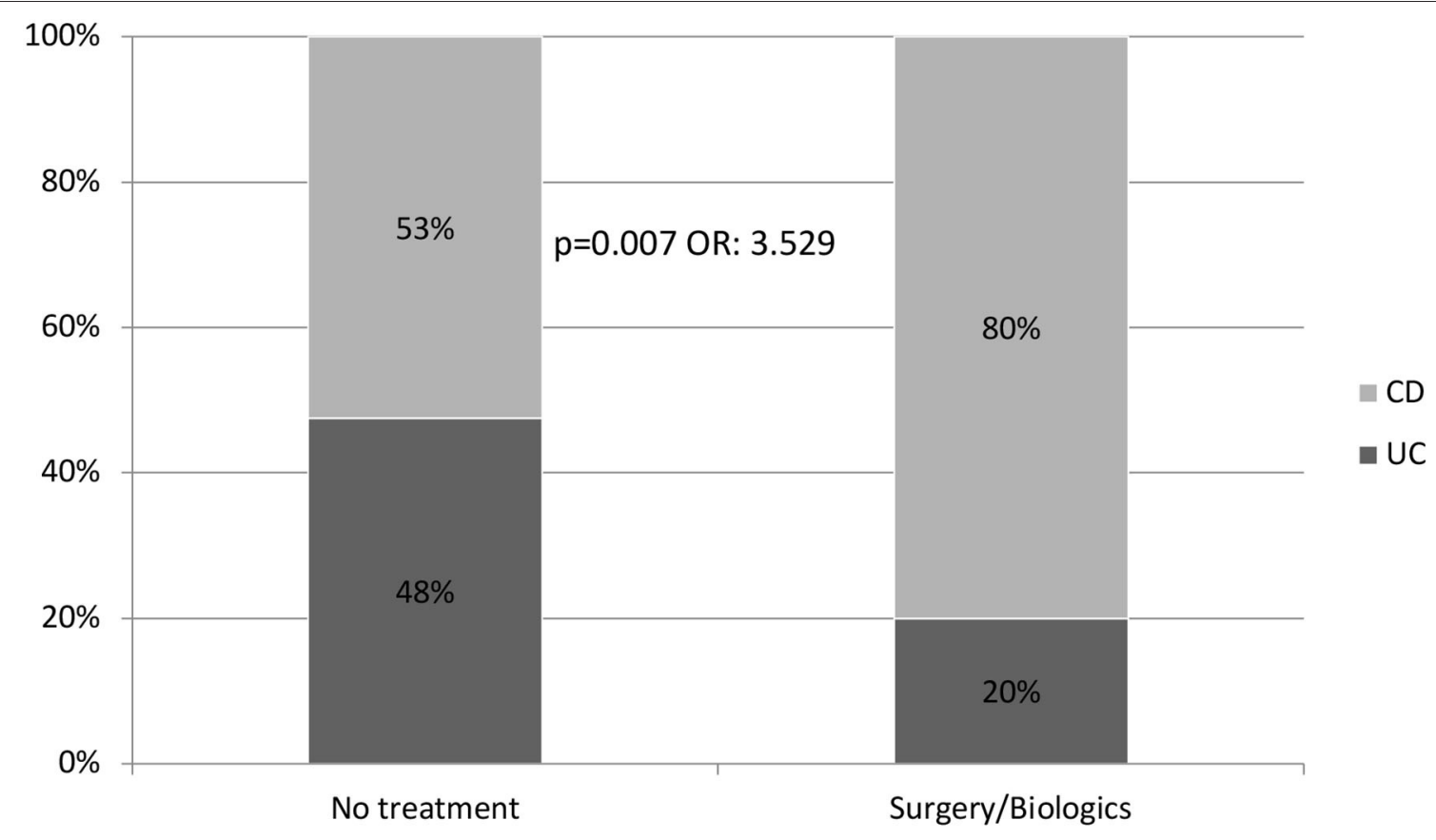

FIGURE 2 | Probability of receiving biological treatment and/or surgery during follow-up after receiving steroids (89 patients).

does not predict the efficacy of this strategy, which is defined as the subsequent requirement of treatment with biological drugs or surgery.

Perianal disease, young age at diagnosis, and the need for corticosteroids appear to be risk factors in patients with CD; therefore, we attempted to identify the criteria and clinical factors associated with a more aggressive course to coincide with the emergence of more effective therapies $(15,16)$. In our cohort, this variable was not associated with a subsequent need for corticosteroids once the patient is already on immunosuppressive therapy. In addition, the use of corticosteroids at diagnosis did not predict the need for subsequent rescue therapies once these corticosteroids were used in our patients. However, once the patient is receiving IMM treatment, as is the case with our cohort, the use of corticosteroids should be carefully evaluated. At no instance should more than 1 cycle of corticosteroid (preferably of low-bioavailability) be used if other therapeutic options that are more effective in the long-term have not been optimized, such as the use of biological drugs and surgery.

The overall efficacy of corticosteroid use in alreadyimmunosuppressed patients with UC or CD, which was defined in our study as having no need for any other type of treatment throughout the follow-up, was only 35\%; therefore, $65 \%$ of patients receiving corticosteroids will require a new cycle of treatment with corticosteroids, biological drugs, or surgery.

The efficacy of this course of corticosteroids for the long-term in our cohort was significantly different between patients with UC and CD. A patient with CD who needs corticosteroids is 3.5 times more likely to need rescue therapy with biological drugs or surgery than a patient with UC ( $p=0.007$, OR: 3.529$)$. In addition, patients with $\mathrm{CD}$ also have a significantly higher risk of requiring more than one cycle of corticosteroids compared to patients with UC.

The role of low-bioavailability corticosteroids in immunosuppressed patients has not been studied. In our cohort, treatment with low-bioavailability corticosteroids in patients with either UC or CD did not predict the use of subsequent salvage therapy when compared to treatment with systemic corticosteroids. Thus, the severity of the flare-up is inadequate to identify the subgroup of patients in which a corticosteroid cycle will be effective. Once we used corticosteroids, we found no differences in the different variables when trying to predict which patients would benefit from this strategy.

Our results indicate that the patients who will need to use corticosteroids the most in the immunosuppressed situation (EC B2-B3) will also be the ones less responsive in the longterm and require early biological treatment or rescue surgery. Therefore, the strategy of using corticosteroids in patients already on IMM treatment may be used most effectively in patients with UC whose flare-up is controlled with low-bioavailability corticosteroids (fewer side-effects). Moreover, the durability of the effect of corticosteroids is greater in these patients with UC than patients with $\mathrm{CD}$.

There are no many studies in the literature that analyze the efficacy of corticosteroids in patients with IMM treatment with which to compare our results; therefore, we believe that data from other larger population cohorts or prospective scenarios are needed to confirm our results. Our work is the first in the literature to show efficacy data and risk factors that are predictive of favorable clinical progress in this specific scenario. We acknowledge the that there are limitations in our study. In fact, there have been many changes in practice 


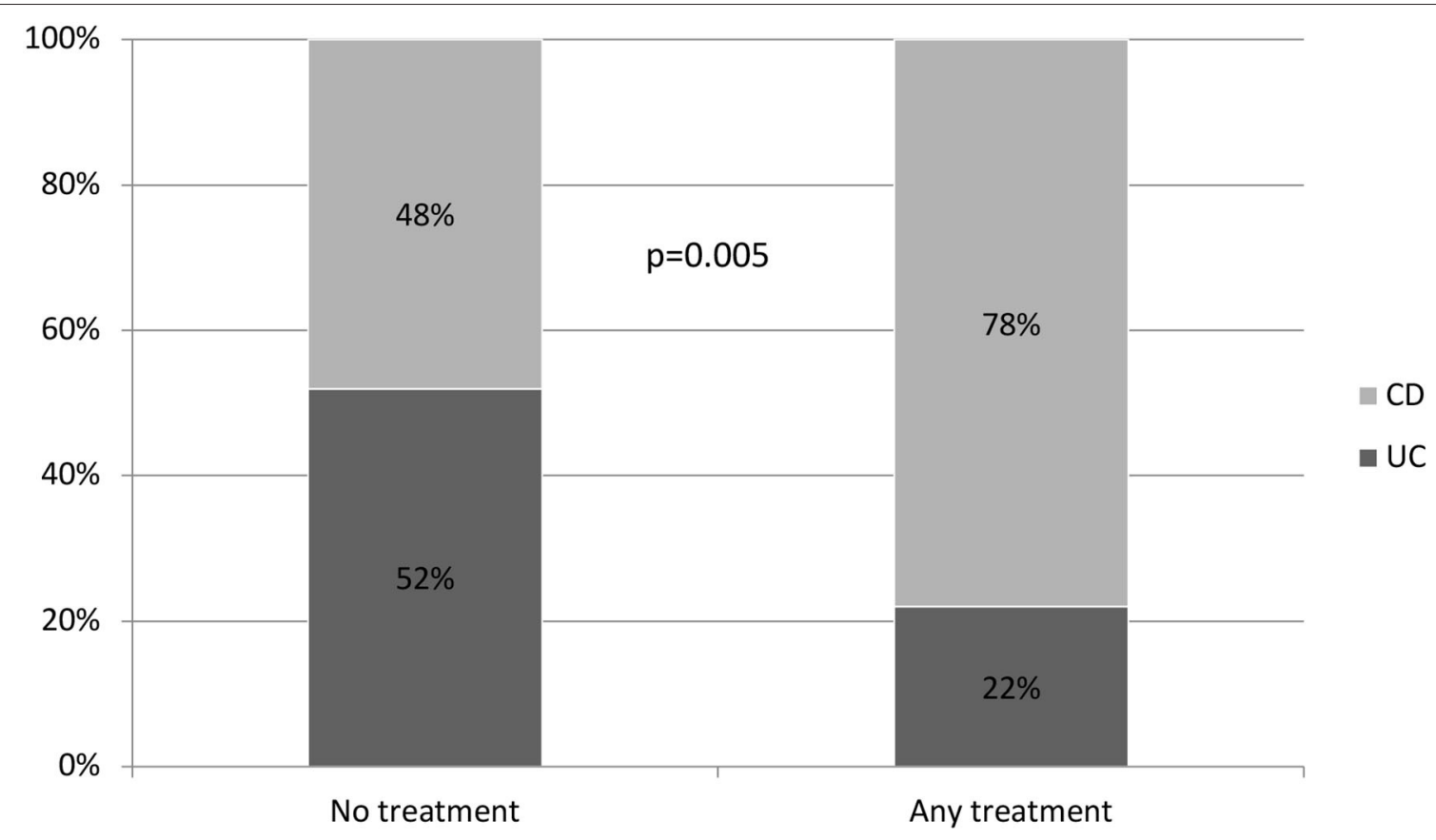

FIGURE 3 | Probability of NO treatment at all (No biological drug, surgery, or corticosteroids).

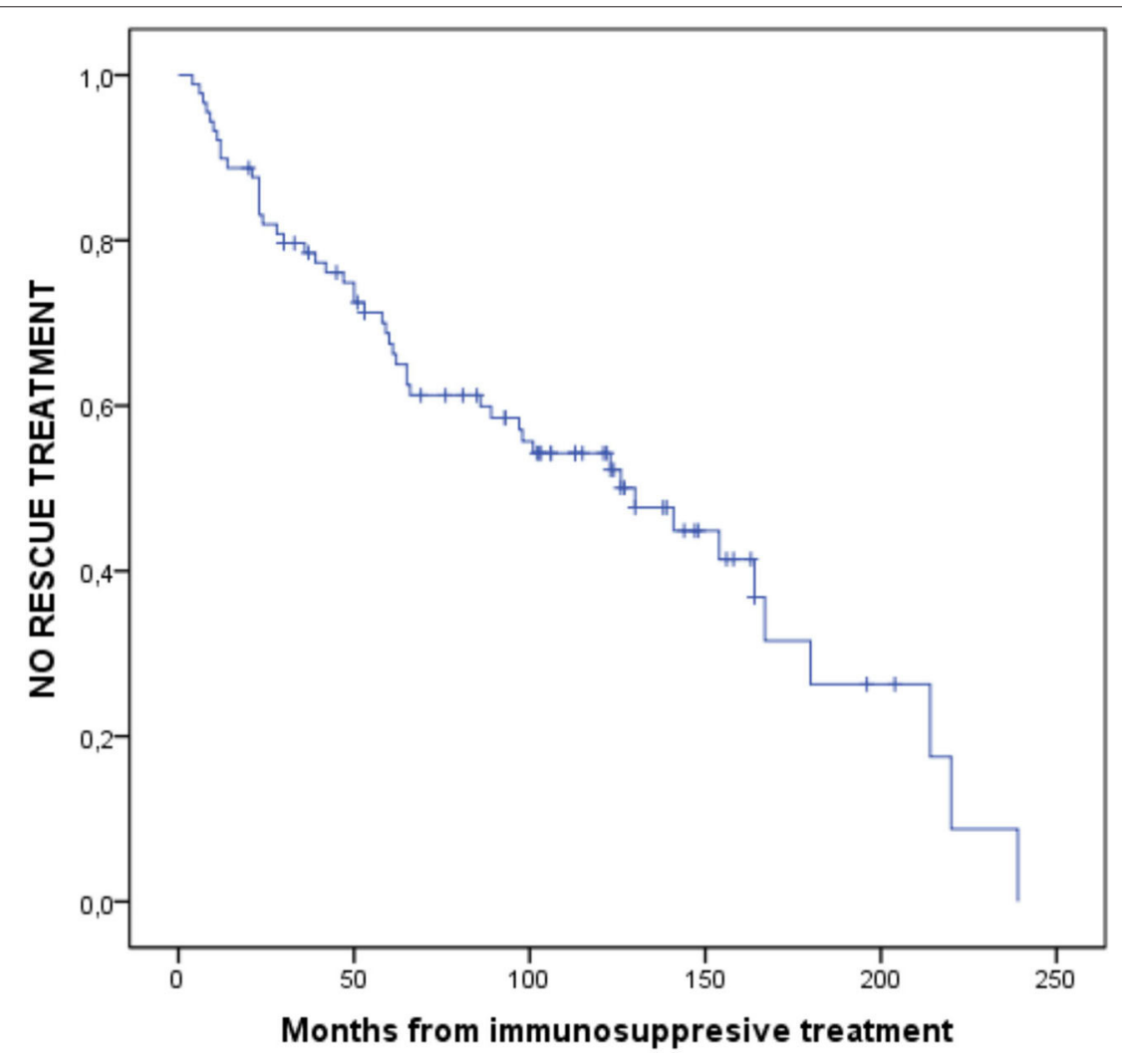

FIGURE 4 | Probability of NO rescue therapy from IMM treatment to the end of follow-up. 


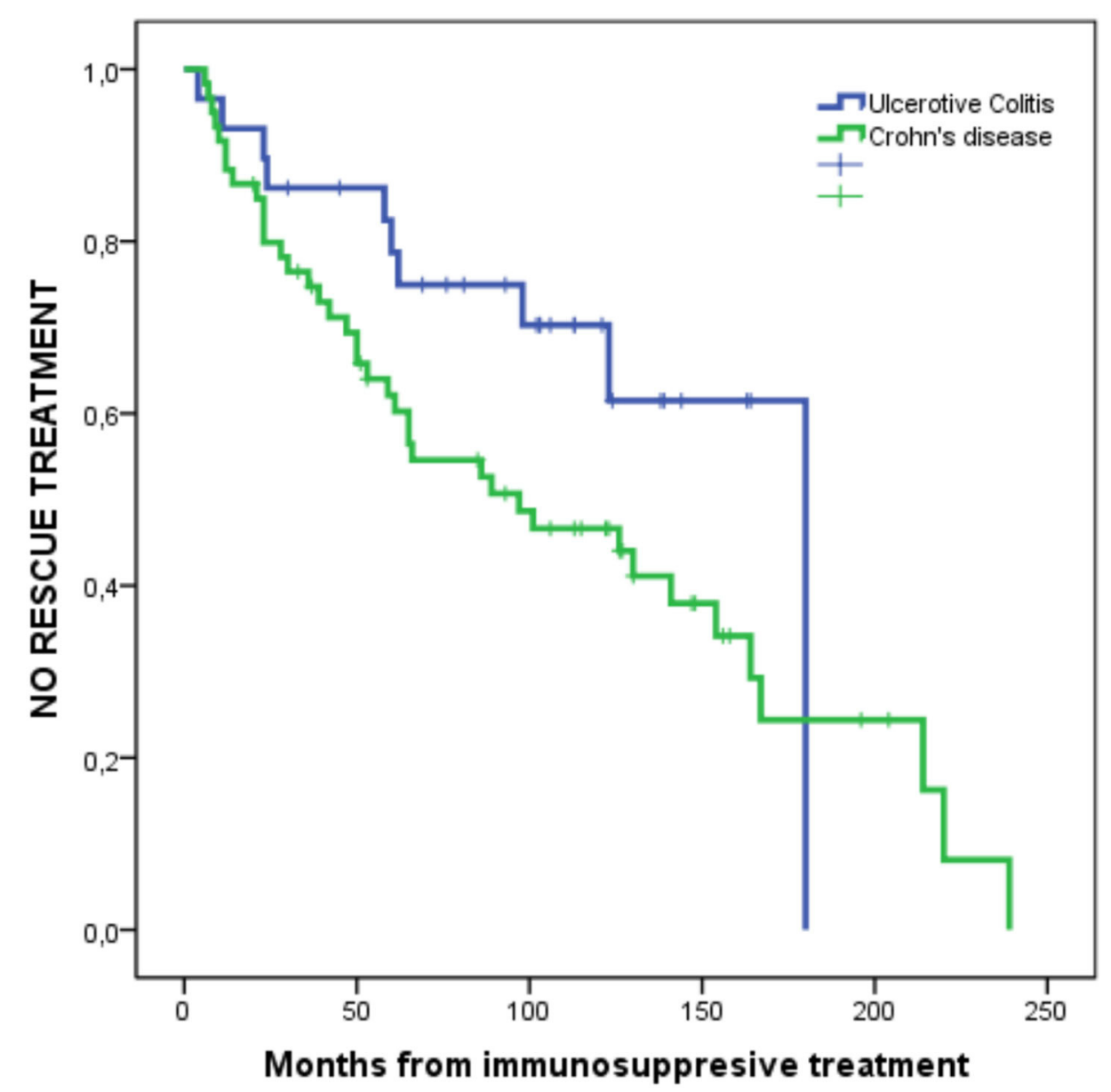

FIGURE 5 | Probability of NO rescue therapy from IMM treatment to the end of follow-up in UC and CD. $P=0.078$.

TABLE 6 | Means and medians of survival times.

\begin{tabular}{|c|c|c|c|c|c|c|}
\hline \multirow[t]{2}{*}{ Current diagnosis } & \multicolumn{3}{|c|}{ Mean a (months) } & \multicolumn{3}{|c|}{ Median (months) } \\
\hline & Estimate & Lower limit & Upper limit & $\begin{array}{l}\text { Estimate } \\
\text { Lower limit }\end{array}$ & Lower limit & Upper limit \\
\hline Ulcerative colitis & 134,96 & 109,21 & 160,73 & 180,00 & - & - \\
\hline Crohn's disease & 111,10 & 88,47 & 133,75 & 97,00 & 32,12 & 161,87 \\
\hline Total & 122,27 & 102,87 & 141,68 & 130,00 & 82,79 & 177,21 \\
\hline
\end{tabular}

${ }^{a}$ The estimate is restricted to the longest survival time if this was recorded.

during the 50 years observation period, and the retrospective design limits the analysis. However, we think these data add information to our knowledge of natural history of IBD under immunosuppressive treatment.

\section{CONCLUSIONS}

More than half of our patients who were in established IMM treatment required treatment with systemic or low-bioavailability corticosteroids throughout their subsequent follow-up. The patients' $\mathrm{B} 2-\mathrm{B} 3 \mathrm{CD}$ pattern and previous use of biological drugs were the only associated risk factors.

This drug strategy was clearly effective only in 35\% (1/3) of the patients treated with corticosteroids; the remaining patients needed further courses of corticosteroids, biological drugs, or surgery. It seems that most flare-ups in IBD patients under immunosuppressants lead finally to biological and/or surgical therapies, and as steroids have significant toxicity, a different strategy could be more adequate, such as directly 
TABLE 7 | Percentils.

\begin{tabular}{lccc}
\hline Current diagnosis & $\mathbf{2 5 . 0} \%$ & $\mathbf{5 0 . 0} \%$ & $\mathbf{7 5 . 0} \%$ \\
\cline { 2 - 4 } & Estimate (months) & Estimate (months) & Estimate (months) \\
\hline Ulcerative colitis & 180 & 180 & 62 \\
Crohn's disease & 167 & 97 & 36 \\
Total & 214 & 130 & 47 \\
\hline
\end{tabular}

switching to biologics or considering surgery, depending on individual factors.

Patients with $\mathrm{CD}$ who require corticosteroids in this specific scenario are 3.5 times more likely to need rescue therapy with biological drugs or surgery than patients with UC; this is reflected in survival curves during follow-up, where the $50 \%$ probability of not receiving any rescue therapy is $83(180-97)$ months longer in patients with UC than patients with CD.

\section{REFERENCES}

1. Truelove SC, Witts SJ. Cortisone in ulcerative colitis; final report on a therapeutic trial. Br Med J. (1955) 2:1041-8. doi: 10.1136/bmj.2.4947.1041

2. Burisch J, Katsanos KH, Christodoulou K, Magro F, Pedersen N, Kieldsen J, et al. Natural disease course of ulcerative colitis during the first five years of follow-up in a European population-based inception cohort-An Epi-IBD Study. JCC. (2018) 3:198-208. doi: 10.1093/ecco-jcc/jjy154

3. Burisch J, Kiudelis G, Kupcinskas L, Kievit HAL, Andersen KW, Andersen V. Natural disease course of Crohn's disease during the first 5 years after diagnosis in a European population-based inception cohort: an Epi-IBD study. Gut. (2018) 68:423-33. doi: 10.1136/gutjnl-2017-315568

4. Gomollón F, Dignass A, Annese V, Tilg H, Van Assche G, Lindsey JO, et al. Third European evidence-based consensus on diagnosis and management of Chron's disease. (2016) part 1: diagnosis and medical management. J Crohns Colitis. (2017) 11:769-84. doi: 10.1093/ecco-jcc/jjw168

5. Harbord M, Eliakim R, Bettenworth D, Karmiris K, Katsanos K, Kopylov U, et al. Third European evidence-based consensus on diagnosis and management of ulcerative colitis. Part 2: current management. J Crohns Colitis. (2017) 11:769-84. doi: 10.1093/ecco-jcc/jjx009

6. Gomollón F, García-López S, Sicilia B, Gisbert JP, Hinojosa J. Therapeutic guidelines on ulcerative colitis: a GRADE methodology based effort of GETECCU. Gastroenterol Hepatol. (2013) 36:10414. doi: 10.1016/j.gastrohep.2012.09.006

7. Ardizzone S, Manconi G, Russo A, Imbesi V, Colombo E, Bianchi Porro G. Randomised controlled trial of azathioprine and 5aminosalicylic acid in steroid dependent ulcerative colitis. Gut. (2006) 55:47-53. doi: 10.1136/gut.2005.068809

8. Sandborn WJ, Feagan BG, Marano C, Zhang H, Strauss R, Johanns J, et al. Subcutaneous golimumab induces clinical response and remission in patients with moderate-to-severe ulcerative colitis. Gastroenterology. (2014) 146:85-95. doi: 10.1053/j.gastro.2013.05.048

9. Feagan BG, Rutgeerts P, Sands BE, Hanauer S, Colombel JF, Sandborn WJ, et al. Vedolizumab as induction and maintenance therapy for ulcerative colitis. N Engl J Med. (2013) 369:699-710. doi: 10.1056/NEJMoa1215734

\section{DATA AVAILABILITY STATEMENT}

The raw data supporting the conclusions of this article will be made available by the authors, without undue reservation.

\section{ETHICS STATEMENT}

The studies involving human participants were reviewed and approved by Ethics Committee Hospital Universitario de Burgos. The patients/participants provided their written informed consent to participate in this study.

\section{AUTHOR CONTRIBUTIONS}

All authors listed have made a substantial, direct and intellectual contribution to the work, and approved it for publication.

10. Sandborn WJ, Su C, Sands BE, D'Haens GR, Vermeire S, Schreiber S, et al. Tofacitinib as induction and maintenance therapy for ulcerative colitis. $N$ Engl J Med. (2017) 376:1723-36. doi: 10.1056/NEJMoa1606910

11. Sandborn WJ, Gasink C, Gao LL, Blank MA, Johanss J, Guzzo C, et al. Ustekinumab induction and maintenance therapy in refractory Crohn's disease. N Engl J Med. (2012) 367:1519-28. doi: 10.1056/NEJMoa1203572

12. Targownik LE, Leung S, Lix LM, Singh H, Bernstein CN. Persistence with immunomodulator monotherapy use and incidence of therapeutic ineffectiveness among users of immunomodulator monotherapy in IBD. Am J Gastroenterol. (2018) 113:1206-16. doi: 10.1038/s41395-018-0108-6

13. Camus M, Seksik P, Bourrier A, Nion-Larmurier I, Sokol H, Baumer $\mathrm{P}$, et al. Long-term outcome of patients with Crohn's disease who respond to azathioprine. Clin Gastroenterol Hepatol. (2013) 11:38994. doi: $10.1016 /$ j.cgh.2012.10.038

14. Blonski W, Buchner AM, Lichtenstein GR. Clinical predictors of aggressive/disabling disease: ulcerative colitis and Crohn disease. Gastroenterol Clin North Am. (2012) 41:443-62. doi: 10.1016/j.gtc.2012.01.008

15. Loly C, Belaiche J, Louis E. Predictors of severe Crohn's disease. Scand J Gastroenterol. (2008) 43:948-54. doi: 10.1080/00365520801957149

16. Seksik P, Loftus EV, Beaugerie L, Harmsen WS, Zinsmeister AR, Cosnes, et al. Validation of predictors of 5-year disabling CD in a population based cohort from Olmsted County, Minnesota, 1983-1986. Gastroenterology. (2007) 132:A17. doi: 10.1016/S0016-5085(07)60009-2

Conflict of Interest: The authors declare that the research was conducted in the absence of any commercial or financial relationships that could be construed as a potential conflict of interest.

Copyright (C) 2021 Sicilia, Arias, Hontoria, García, Badia and Gomollón. This is an open-access article distributed under the terms of the Creative Commons Attribution License (CC BY). The use, distribution or reproduction in other forums is permitted, provided the original author(s) and the copyright owner(s) are credited and that the original publication in this journal is cited, in accordance with accepted academic practice. No use, distribution or reproduction is permitted which does not comply with these terms. 